\title{
O comportamento recente da taxa real de juros no Brasil: existe espaço para uma queda maior da taxa de juros?
}

José Luis Oreiro*

O Banco Central do Brasil iniciou o recente ciclo de "flexibilização" da política monetária em outubro de 2005 quando reduziu a meta de taxa de juros Selic de 19,75\% a.a. para 19,5\% ao ano. Desde então, a cada reunião do Comitê de Política Monetária (Copom), a meta de taxa nominal de juros tem sido reduzida, de tal forma que, em setembro do corrente ano, a meta da Selic alcançou o patamar de 14,25 \% a.a., o menor nível nominal da história do Copom. Sendo assim, o Banco Central do Brasil promoveu uma redução de mais de 5 p.p. da taxa nominal de juros num espaço de um ano, o que seria um sinal inequívoco da "flexibilização" da política monetária, contrariando, portanto, os críticos do Banco Central que reclamam de um excesso de conservadorismo na condução da política monetária.

Para que possamos avaliar o grau no qual a política monetária foi flexibilizada no passado recente, devemos, no entanto, olhar para o comportamento da taxa real de juros, e não para o comportamento da taxa nominal. Isto porque as decisões de dispêndio agregado, as quais tem influência direta sobre o nível de atividade econômica e sobre a taxa de inflação, dependem da taxa real de juros e não da taxa nominal.

Em termos conceituais, a taxa real de juros pode ser aproximada pela diferença entre a taxa nominal de juros e a taxa esperada de inflação. Aqui nos deparamos com o primeiro problema: como avaliar as expectativas de inflação dos agentes econômicos? Uma primeira forma de lidar com esse problema é assumir que os agentes econômicos formam as suas expectativas de inflação tomando como base o comportamento passado da mesma, ou seja, que é válida a hipótese de expectativas adaptativas.

Nesse contexto, se supõe que a taxa esperada de inflação para os próximos 12 meses pode ser aproximada pela taxa de inflação efetivamente ocorrida nos 12 meses anteriores. Trata-se do método backward-looking para o cálculo da taxa real de juros. Uma segunda maneira de lidar com esse problema é obter alguma informação a respeito da taxa de inflação que os agentes econômicos estão antecipando para os próximos 12 meses. No Brasil essa informação é coletada por intermédio da Gerência Executiva de Relacionamento com

\footnotetext{
* Professor do Departamento de Economia da Universidade Federal do Paraná (UFPR). Pesquisador do CNPq e Coordenador do boletim de conjuntura Economia \& Tecnologia. Endereço eletrônico: joreiro@ufpr.br
} 
Investidores (Gerin) do Banco Central. Trata-se de uma pesquisa feita junto a uma série de instituições financeiras, na qual o Banco Central procura averiguar a taxa de inflação que essas instituições estão projetando para o futuro. Essas expectativas são utilizadas pelo Banco Central, entre outras variáveis, como subsídio para a tomada de decisão a respeito da meta de Selic em cada reunião do Copom. Este é o método forward-loooking para o cálculo da taxa real de juros.

O gráfico 1 apresenta a evolução da taxa real de juros no Brasil no período compreendido entre janeiro de 2004 e setembro de 2006 com base no método forward-looking. Tal como podemos observar, a taxa real de juros alcançou o valor máximo de 14,39\% a.a. em setembro de 2005. A partir desta data a taxa real de juros apresenta uma consistente tendência de queda, chegando ao patamar de 9,46\% a.a. em setembro de 2006 .

Gráfico 1. Evolução da Taxa Real de Juros no Brasil (jan./2004-set./2006)

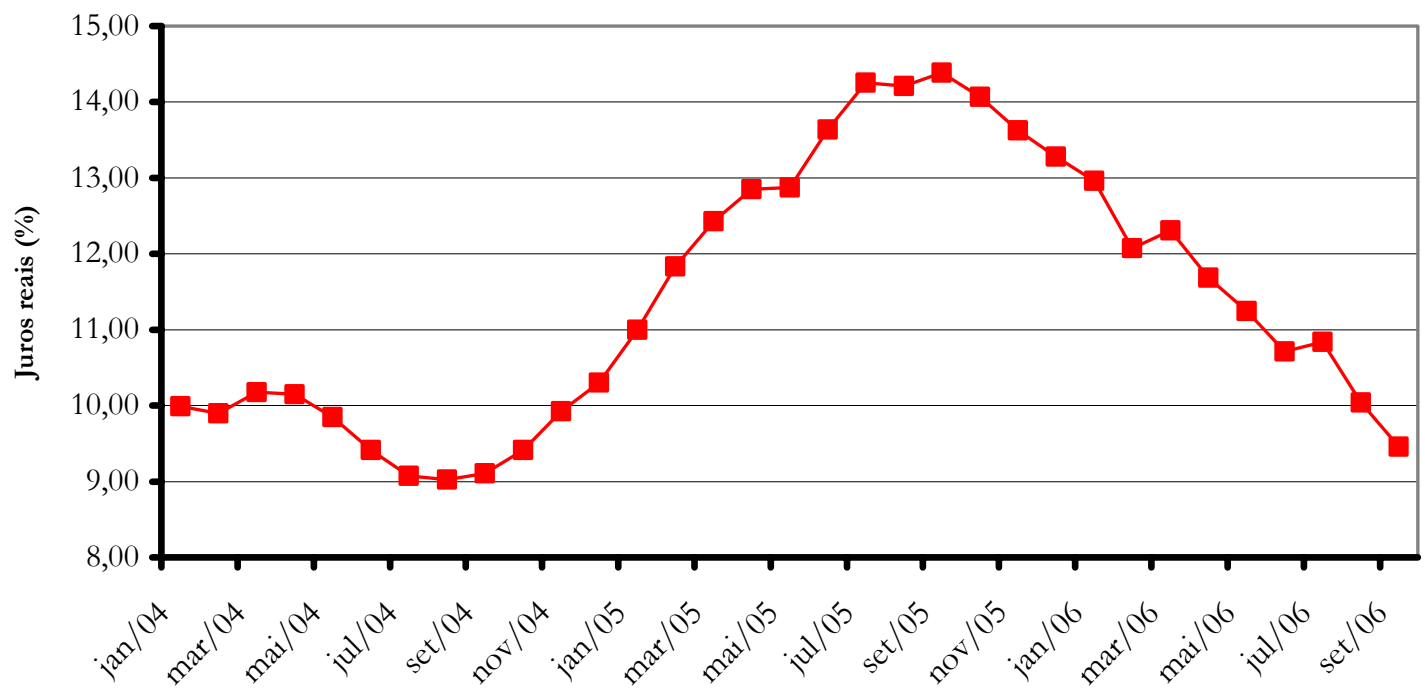

Fonte: calculado pelo autor a partir dos dados disponibilizados pelo Banco Central.

Uma outra observação importante a respeito do comportamento recente da taxa real de juros é que o patamar atual da referida taxa é praticamente o mesmo que prevalecia no momento em que se iniciou o último ciclo de elevação da taxa de juros nominal por parte do Banco Central. Com efeito, este último ciclo de elevação da taxa nominal de juros foi iniciado em outubro de 2004, quando a meta da taxa Selic foi aumentada de 16\% a.a. para 16,25\% a.a. Naquele momento, a taxa real de juros calculada por intermédio do método forward-looking era de $9,41 \%$ ao ano. 
Tendo em vista essas observações, será que o atual ciclo de redução da taxa nominal de juros estaria chegando ao fim? Em outras palavras, será que o valor da taxa real de juros abaixo do qual começam a surgir pressões inflacionárias, ou seja, aquilo que os economistas costumam denominar de taxa natural de juros, é de 9,5\% a.a. no caso da economia brasileira?

Como é sabido, o conceito de taxa natural de juros é devido a Wicksell (1997). Segundo este autor, a taxa natural de juros seria o "preço" que compatibiliza as decisões de poupança e de investimento dos agentes econômicos quando a economia está operando num contexto de pleno-emprego dos fatores de produção. Poucas tentativas têm sido feitas no sentido de calcular o valor da taxa natural de juros para a economia brasileira. Uma notável exceção é o trabalho de Muinhos \& Nakane (2005) que, tomando como base uma estimativa da Curva IS e do produto potencial da economia brasileira, chegam a um valor de 11,11\% a.a para a taxa real de juros de equilíbrio. Nesse contexto, o nível corrente da taxa real de juros no Brasil estaria abaixo do seu equilíbrio de longo prazo, sinalizando assim que a atual política monetária é, na verdade, uma política expansionista.

O conceito de taxa natural de juros não é, no entanto, aplicável aos países emergentes que possuem a conta de capitais aberta, como é o caso da economia brasileira atualmente. A teoria econômica convencional diz que, no caso de pequenas economias abertas operando num contexto de ampla liberdade de movimentação de capitais de curto prazo, a taxa real de juros de equilíbrio é constituída pela soma entre a taxa real de juros internacional e o prêmio de risco-país. Trata-se do nível da taxa real de juros que, se obtido, faz com que o balanço de pagamentos permaneça em equilíbrio, não apresentando déficits ou superávits.

Uma estimativa conservadora da taxa real de juros de equilíbrio prevalecente nos países desenvolvidos é que esta se situaria em torno de $2 \%$ ao ano. Considerando que nos últimos 12 meses o prêmio de risco país tem oscilado em torno de 250 pontos base, então chegamos a um valor de 4,5\% ao ano. Se levarmos em conta o fato levantado por Brainard (1967) de que existe incerteza considerável a respeito dos efeitos de mudanças na política econômica e que, portanto, não podemos estar absolutamente certos de que uma taxa real de juros de 4,5\% ao ano não geraria um desequilíbrio persistente no balanço de pagamentos da economia brasileira; então, a título de precaução, devemos acrescentar 100 ou 200 pontos base à estimativa anterior ${ }^{26}$. Dessa forma, obtemos uma estimativa extremamente

${ }^{26}$ Agradeço ao Professor Fernando de Holanda Barbosa (EPGE-FGV/RJ) a sugestão da adição de uma margem de segurança para captar os efeitos da incerteza sobre os efeitos da política econômica. 
conservadora para a taxa real de juros de equilíbrio da economia brasileira da ordem de $6,5 \%$ ao ano.

Esses cálculos simples nos mostram que existe ainda um espaço considerável para a queda da taxa real de juros no Brasil da ordem de 300 pontos base e que, portanto, a Selic nominal pode cair até um patamar de 10,5\% a.a., supondo uma meta de inflação de longo prazo da ordem de 4\% ao ano. Se o raciocínio feito até aqui estiver correto então a política monetária conduzida pelo Banco Central não sofre apenas de um "excesso de conservadorismo" como também, e principalmente, está sendo conduzida de forma completamente equivocada. Isto porque a política monetária está sendo conduzida com base na suposição implícita de que a taxa real de juros de equilíbrio da economia brasileira está em torno de 10 a 11\% a.a, quando na verdade a taxa de equilíbrio não chega sequer a $7 \%$ ao ano.

O resultado mais importante desse equívoco é a brutal apreciação da taxa real de câmbio observada na economia brasileira nos últimos 2 anos. Isso porque existe um diferencial entre a taxa real de juros efetiva e a taxa real de juros de equilíbrio de aproximadamente 300 pontos base nas condições atuais. Esse diferencial de juros tem dois efeitos. Em primeiro lugar, gera uma forte entrada de capitais de curto prazo, a qual contribui para apreciar o câmbio pelo lado da conta de capitais do balanço de pagamentos. Em segundo lugar, o elevado patamar da taxa real de juros é uma das razões pelas quais a economia brasileira tem apresentado um crescimento medíocre nos últimos anos. O baixo crescimento também contribui para a apreciação do câmbio à medida que reduz a taxa de aumento das importações, mantendo assim o elevado patamar do superávit da balança comercial. 
Gráfico 2. Relação Câmbio Efetivo/Salário Real da Indústria (jan./2004-jan./2006)

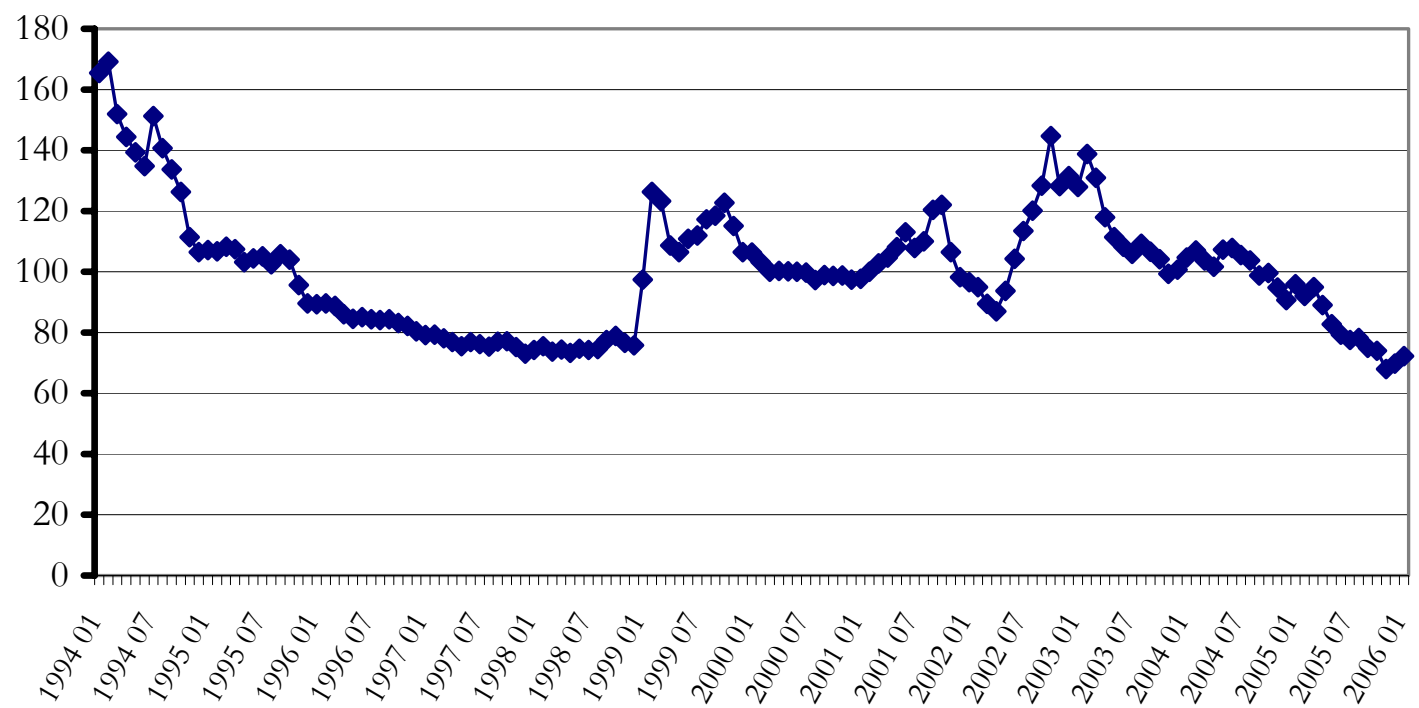

Fonte: Instituto de Pesquisa Econômica Aplicada (IPEA).

Nota: *Salário real médio mensal da industria. **Taxa real de câmbio efetiva mensal-INPC - $(2000=100)$

Tal como podemos observar no gráfico 2 apresentado, a taxa real efetiva de câmbio deflacionada pelo salário real médio mensal da indústria observada no início de 2006 encontra-se abaixo do valor observado durante o regime de câmbio administrado (19951998). Estes dados não deixam dúvidas de que a taxa real de câmbio está abaixo do seu valor de equilíbrio de longo prazo, sendo apenas uma questão de tempo para que isso se manifeste em termos de uma redução consistente do saldo da balança comercial.

\section{Referências Bibliográficas}

BRAINARD, W. (1967). "Uncertainty and the Effectiveness of Policy". In: American Economic Review, Maio.

MUINHOS, M. K.; NAKANE, M. (2005). "Comparing Equilibrium Interest Rates: stylized facts about Brazilian figures". Mimeo.

WICKSELL, K. (1997). "A Influência da Taxa de Juros sobre os Preços" In: Carneiro, R. (org.). Os Clássicos de Economia, Vol. 1, São Paulo: Ed. Ática. 
